\title{
Final treatment outcomes of multidrug- and extensively drug-resistant tuberculosis patients in Latvia receiving delamanid-containing regimens
}

To the Editor:

Latvia is a high-priority country in the fight against tuberculosis (TB) in Europe, with an estimated TB incidence of 41 per 100000 in 2015 [1]. In spite of an improving TB control programme [2] and cure rates reaching $80 \%$ for new and retreatment TB cases notified in 2014, multidrug-resistant (MDR-) TB (defined as TB resistant to rifampicin and isoniazid) rates in Latvia remain high [1]. An estimated $8 \%$ of new cases and $30 \%$ of retreatment TB cases were at least rifampicin-resistant (RR) in 2015 [1]. Cure rates in Latvia were $68 \%$ for the 2013 RR/MDR-TB cohort [1]. Of all the MDR-TB patients registered in 2015, $25 \%$ had extensively drug-resistant (XDR-) TB (defined as MDR-TB with additional resistance to a fluoroquinolone and a second-line injectable drug) [1].

Delamanid (Deltyba), a nitroimidazooxazole derivative, is an anti-TB drug exhibiting potent in vitro and in vivoantitubercular activity against drug-susceptible and -resistant strains of Mycobacterium tuberculosis $[3,4]$. It was approved in the European Union in 2014 and included in the World Health Organization (WHO)'s MDR-TB treatment guidance [5]. Latvia was among the first countries to initiate treatment with delamanid following its approval in the EU. We present here a retrospective, post-marketing national cohort study describing the final treatment outcomes of MDR- and XDR-TB patients receiving delamanid in Latvia between July 2014 and August 2016.

All diagnosed TB patients and their final treatment outcomes in Latvia are recorded in the National TB Register, which was used as the data source for this study. All cultures positive for Mycobacterium tuberculosis undergo drug susceptibility testing against first-line and second-line drugs. Specimens from suspected MDR-TB cases are tested with the Xpert MTB/RIF assay (Cepheid, Sunnyvale, CA, USA); empirical second-line treatment is started immediately upon receipt of an RR result. Patients are managed in accordance with WHO recommendations and under an expert consilium [6-8].

Patients with laboratory-confirmed MDR-, pre-XDR (defined as MDR-TB with resistance to either a fluoroquinolone or second-line injectable agent, but not both [9]) and XDR-TB were selected for treatment with delamanid when no other treatment options were available, i.e. for reasons of resistance or tolerability.

The following information was recorded from the national TB register for all patients: age, sex, type and category of TB, presence of cavities at the start of treatment, HIV status, body mass index, presence/ absence of diabetes mellitus, TB treatment history, optimised background regimen (OBR) in addition to delamanid, sputum culture status, and final treatment outcome. Data were collected in an MS Excel file (Microsoft version 2010, Redmond, WA, USA) and analysed with descriptive statistics and frequency counts. Approval for the study was received in November 2015 from the University of Latvia ethics committee.

19 patients who received delamanid had final treatment outcomes as of August 2016. Of the 19 patients, 15 (78.9\%) were male. The mean age was 41.5 years (range: 11-66), and 17 (89.5\%) patients were $\geqslant 18$ years of age. All $19(100 \%)$ patients had pulmonary disease, and two (10.5\%) patients had pulmonary

@ERSpublications

Final treatment outcomes from the first cohort of delamanid MDR-TB patients in Latvia support its safety and efficacy http://ow.ly/6Mhy30fPv2f

Cite this article as: Kuksa L, Barkane L, Hittel N, et al. Final treatment outcomes of multidrug- and extensively drug-resistant tuberculosis patients in Latvia receiving delamanid-containing regimens. Eur Respir J 2017; 50: 1701105 [https://doi.org/10.1183/13993003.01105-2017]. 


\begin{tabular}{|c|c|c|c|c|c|c|c|c|c|}
\hline Patient & $\begin{array}{l}\text { Age } \\
\text { years }\end{array}$ & Sex & $\begin{array}{l}\text { Resistance } \\
\text { classification }\end{array}$ & Drug resistance & $\begin{array}{l}\text { Previous } \\
\text { treatment } \\
\text { history }\end{array}$ & $\begin{array}{l}\text { Delamanid treatment } \\
\text { duration in months } \\
\text { (weeks) }\end{array}$ & $\begin{array}{l}\text { Total MDR-TB } \\
\text { treatment duration } \\
\text { in months }\end{array}$ & Companion drugs & $\begin{array}{c}\text { Final treatment outcome } \\
\text { at the end of MDR-TB } \\
\text { treatment }\end{array}$ \\
\hline 1 & 30 & M & Pre-XDR & $\begin{array}{c}\mathrm{H}, \mathrm{R}, \mathrm{E}, \mathrm{Z}, \mathrm{Am}, \mathrm{Km}, \mathrm{Cm} \text {, } \\
\text { PAS }\end{array}$ & $\begin{array}{l}\text { Z, Cm, Mfx, Pto, } \\
\text { Trd, PAS }\end{array}$ & $9(36)$ & 14 & $\begin{array}{c}\text { Z, Cm, Mfx, Pto, } \\
\text { Trd }\end{array}$ & Cured \\
\hline 2 & 63 & M & MDR & $H, R, E$ & $\begin{array}{l}\text { Z, Cm, Lfx, Pto, } \\
\text { Trd, PAS }\end{array}$ & $6(24)$ & 16 & Z, Lfx, Pto, Trd & Cured \\
\hline 3 & 56 & M & XDR & $\begin{array}{l}\mathrm{H}, \mathrm{R}, \mathrm{E}, \mathrm{Am}, \mathrm{Km}, \mathrm{Cm}, \mathrm{Ofx} \text {, } \\
\text { Lfx, Trd, low-dose Mfx }\end{array}$ & $H, R, E, Z$ & $11(44)$ & 0 & $\begin{array}{l}\text { Mfx, Lzd, Pto, } \\
\text { Amx/Clv }\end{array}$ & Cured \\
\hline 4 & 62 & M & Pre-XDR & $\begin{array}{c}\mathrm{H}, \mathrm{R}, \mathrm{E}, \mathrm{Z}, \mathrm{Am}, \mathrm{Km}, \mathrm{Cm}, \\
\text { Pto, Trd }\end{array}$ & $\begin{array}{l}\text { No prior } \\
\text { treatment }\end{array}$ & $10(40)$ & 13 & Z, Mfx, Lzd, PAS & Cured \\
\hline 5 & 66 & M & Pre-XDR & $\mathrm{H}, \mathrm{R}, \mathrm{E}, \mathrm{Z}, \mathrm{Cm}$, Pto, PAS & $\begin{array}{l}\text { No prior } \\
\text { treatment }\end{array}$ & $9(36)$ & 12 & $\begin{array}{c}\text { Z, Am, Lfx, Lzd, } \\
\text { Trd }\end{array}$ & Cured \\
\hline 6 & 44 & M & Pre-XDR & $\begin{array}{c}H, R, E, Z, A m, K m, C m \text {, } \\
\text { Pto }\end{array}$ & $\begin{array}{l}\text { Z, Mfx, Pto, Trd, } \\
\text { PAS }\end{array}$ & $10(40)$ & 16 & $\begin{array}{l}\text { Lfx, Lzd, Trd, } \\
\text { Amx/Clv }\end{array}$ & Lost to follow-up \\
\hline 7 & 25 & M & XDR & $\begin{array}{c}H, R, E, Z, A m, C m, M f x, \\
\text { Pto }\end{array}$ & $\begin{array}{l}\text { Trd, PAS, Lzd, } \\
\text { Bdq, Amx/Clv }\end{array}$ & $3(12)$ & 18 & Trd, PAS, Amx/Clv & Cured \\
\hline 8 & 56 & M & XDR & $\begin{array}{l}H, R, E, Z, K m, \text { Ofx, Lfx, } \\
\text { PAS, low-dose Mfx }\end{array}$ & $H, R, E, Z$ & $9(36)$ & 0 & $\begin{array}{c}\text { Z, Cm, Mfx, Pto, } \\
\text { Trd }\end{array}$ & Cured \\
\hline 9 & 22 & M & XDR & $\begin{array}{c}H, R, E, Z, C m, \text { Ofx, Lfx, } \\
\text { Mfx, PAS }\end{array}$ & $\begin{array}{l}\text { E, Z, Cm, Lfx, } \\
\text { Pto, Trd }\end{array}$ & $6(24)$ & 7 & $\begin{array}{l}\text { Z, Am, Mfx, Lzd, } \\
\text { Pto, Trd }\end{array}$ & Lost to follow-up \\
\hline 10 & 25 & M & XDR & $\begin{array}{c}H, R, Z, K^{\#}, \mathrm{Cm}^{\#}, \text { Ofx } \\
\text { Lfx, Mfx, PAS }\end{array}$ & $H, R, E, Z$ & $9(36)$ & 14 & $\begin{array}{c}\text { Z, Am, Lzd, Pto, } \\
\text { Trd }\end{array}$ & Cured \\
\hline 11 & 48 & M & XDR & $\begin{array}{c}\mathrm{H}, \mathrm{R}, \mathrm{E}, \mathrm{Z}, \mathrm{Am}, \mathrm{Km}, \mathrm{Cm}, \\
\text { Ofx, Lfx, low-dose Mfx, } \\
\text { Pto, Trd, PAS }\end{array}$ & $\begin{array}{l}\text { No prior } \\
\text { treatment }\end{array}$ & $13(52)$ & 13 & $\begin{array}{c}\text { Mfx, Lzd, PAS, } \\
\text { Imp/Cls, Amx/Clv }\end{array}$ & Cured \\
\hline 12 & 13 & $\mathrm{~F}$ & Pre-XDR & $\mathrm{H}, \mathrm{R}, \mathrm{E}, \mathrm{Am}, \mathrm{Km}, \mathrm{Cm}$, Pto & $\begin{array}{l}\text { No prior } \\
\text { treatment }\end{array}$ & $6(24)$ & 11 & $\begin{array}{l}\text { Z, Cm, Mfx, Trd, } \\
\text { Amx/Clv }\end{array}$ & Cured \\
\hline 13 & 56 & M & Pre-XDR & $\begin{array}{c}\text { H, R, E, Z, Ofx, Lfx, } \\
\text { low-dose Mfx, Pto, PAS }\end{array}$ & $\begin{array}{l}\text { No prior } \\
\text { treatment }\end{array}$ & $14(58)$ & 0 & $\begin{array}{l}\text { Mfx, Lzd, Trd, } \\
\text { Amx/Clv }\end{array}$ & Cured \\
\hline 14 & 11 & $\mathrm{~F}$ & XDR & $\begin{array}{l}\mathrm{H}, \mathrm{R}, \mathrm{E}, \mathrm{Z}, \mathrm{Am}, \mathrm{Km}, \text { Ofx } \\
\text { Lfx, low-dose Mfx, Pto }\end{array}$ & $\begin{array}{l}\text { No prior } \\
\text { treatment }\end{array}$ & $6(24)$ & 0 & $\begin{array}{c}\text { Z, Cm, Mfx, Lzd, } \\
\text { Trd }\end{array}$ & Cured \\
\hline 15 & 35 & M & XDR & $\begin{array}{c}H, R, E, Z, C m, \text { Ofx, Lfx, } \\
\text { Mfx, Pto, PAS }\end{array}$ & $\begin{array}{l}\text { Z, Am, Pto, Trd, } \\
\text { Lzd, Amx/Clv }\end{array}$ & $11(44)$ & 19 & $\begin{array}{l}\text { Z, Am, Lzd, Trd, } \\
\text { Amx/Clv }\end{array}$ & Cured \\
\hline 16 & 53 & M & MDR & $H, R, E, Z$ & $\begin{array}{l}\text { E, Z, Lfx, Pto, } \\
\text { Trd, PAS }\end{array}$ & $2(7)$ & 12 & $\begin{array}{l}\text { Z, Lfx, Lzd, Pto, } \\
\text { Trd }\end{array}$ & Lost to follow-up \\
\hline 17 & 27 & $\mathrm{~F}$ & Pre-XDR & $\begin{array}{c}H, R, E, Z, O f x, L f x, M f x \\
\text { Pto }\end{array}$ & $\begin{array}{l}\text { Am, Mfx, Trd, } \\
\text { Lzd, Amx/Clv }\end{array}$ & $6(24)$ & 18 & $\begin{array}{l}\text { Am, Lzd, Trd, } \\
\text { Amx/Clv }\end{array}$ & Cured \\
\hline 18 & 61 & M & Pre-XDR & $\begin{array}{c}\mathrm{H}, \mathrm{R}, \mathrm{E}, \mathrm{Z}, \mathrm{Am}, \mathrm{Km}, \mathrm{Cm} \text {, } \\
\text { PAS }\end{array}$ & $\begin{array}{l}\text { Mfx, Pto, Trd, } \\
\text { Amx/Clv }\end{array}$ & $6(24)$ & 19 & Lfx, Lzd, Pto, Trd & Cured \\
\hline 19 & 36 & $\mathrm{~F}$ & XDR & $\begin{array}{c}H, R, E, Z, A m, K m, C m, \\
\text { Ofx, Lfx, Mfx, Pto, Trd, } \\
\text { PAS }\end{array}$ & $\begin{array}{c}\text { Trd, Lzd, Bdq, } \\
\text { Amx/Clv, Imp/Cls }\end{array}$ & $3(12)$ & 16 & $\begin{array}{l}\text { Lzd, Imp/Cls, } \\
\text { Amx/Clv }\end{array}$ & Cured \\
\hline \multicolumn{10}{|c|}{$\begin{array}{l}\text { Cured: treatment completed as recommended by the national policy without evidence of failure, and three or more consecutive cultures taken at least } 30 \text { days apart are negative after the } \\
\text { intensive phase. TB: tuberculosis; MDR: multidrug-resistant; XDR: extensively drug-resistant; H: isoniazid; R: rifampicin; E: ethambutol; Z: pyrazinamide; Am: amikacin; Km: kanamycin } \\
\text { Cm: capreomycin; PAS: para-aminosalicylic acid; Mfx: moxifloxacin; Pto: protionamide; Trd: terizidone; Lfx: levofloxacin; Ofx: ofloxacin; Lzd: linezolid; Amx: amoxicillin; Clv: clavulanate } \\
\text { Bdq: bedaquiline; Imp: imipenem; Cls: cilastatin. \#: inconsistent susceptibility test results. }\end{array}$} \\
\hline
\end{tabular}


with additional extrapulmonary disease (the first with intestinal TB, and the second with urogenital TB and a submandibular TB positive abscess). 13 patients (68.4\%) had received previous treatment for TB including one or more second-line TB drugs. Of the 19 patients, two (10.5\%) had MDR-TB, eight $(42.1 \%)$ had pre-XDR-TB, and nine (47.4\%) had XDR-TB. Only one patient (5.3\%) was HIV-positive, and no patient $(0.0 \%)$ had diabetes. $11(57.9 \%)$ patients had no cavities present, five $(26.3 \%)$ had unilateral cavities, and three (15.8\%) had bilateral cavities (table 1).

The OBR included terizidone $(n=15,78.9 \%)$, linezolid $(n=14,73.7 \%)$, pyrazinamide $(n=11,57.9 \%)$, moxifloxacin $(n=9,47.4 \%)$, amoxicillin/clavulanate $(n=9,47.4 \%)$, protionamide $(n=8,42.1 \%)$, amikacin $(n=5,26.3 \%)$, levofloxacin $(n=5,26.3 \%)$, capreomycin $(n=4,21.1 \%)$, para-aminosalicylic acid $(n=3,15.8 \%)$, and imipenem/cilastatin $(\mathrm{n}=2,10.5 \%)$.

The mean treatment duration with delamanid was 31.2 weeks (range 7-58), and 16 (84.2\%) patients received delamanid for at least 24 weeks. Three patients $(15.8 \%)$ received delamanid for $<24$ weeks. In two patients, delamanid replaced bedaquiline treatment after the completion of a full course of bedaquiline. In the third case, the patient's delamanid treatment was stopped after 2 months when drug susceptibility testing results became available and an effective MDR-TB regimen could be composed without delamanid. 10 patients (52.6\%) received delamanid for longer (36-58 weeks) than the label-approved 24-week treatment duration; all 10 had either pre-XDR-TB $(n=5)$ or XDR-TB $(n=5)$.

Final treatment outcomes were as follows: 16 patients (84.2\%) were classified as cured (treatment completed as recommended by the national policy without evidence of failure, and three or more consecutive cultures taken at least 30 days apart are negative after the intensive phase), three patients (15.8\%) were lost to follow-up, and there were no deaths or treatment failures. Amongst the patients lost to follow-up, all three were culture negative for M. tuberculosis prior to default, and their total MDR-TB treatment duration ranged from 7 to 16 months. The overall MDR-TB treatment duration for the 16 cured patients ranged from 11 to 19 months (mean 15 months). Following the Latvian national programme recommendations following cure, patients are followed up every 6 months, including sputum evaluation. To date, no relapse has been registered among the 19 patients.

ECG was performed typically once a month, or more often if deemed necessary, during patients' MDR-TB therapy. The QTcF (QT interval corrected by Fridericia's method) value did not exceed $500 \mathrm{~ms}$ for any patient $(0.0 \%)$ and hepatotoxicity was not reported for any patient. No other clinically relevant adverse events were attributed to delamanid treatment.

This report represents the first cohort of final treatment outcomes for delamanid patients in the Latvian programmatic setting. The 19 patients in this cohort study represent severe MDR-TB cases, with 17 patients $(89.5 \%)$ having pre-XDR or XDR-TB (eight (42.1\%) with unilateral or bilateral cavitary disease) and two (10.5\%) with additional extrapulmonary disease. Thus, the prognosis for these patients was expected to be poor. However, $84.2 \%$ (16 out of 19) of patients were cured and, based on the last culture result available, patients lost to follow-up were all sputum negative. In contrast, a study of 1779 registered MDR-TB patients in Latvia from 2000 to 2010 showed cure rates of $67 \%$ and $50 \%$ for MDR-TB and XDR-TB, respectively [10].

Many of the patients included in the present cohort required delamanid treatment beyond 24 weeks, but the overall MDR-TB treatment duration in patients that completed MDR-TB therapy was shorter (mean 15 months, range 11-19 months) than the standard 18-24 months. Reasons for the shorter overall MDR-TB treatment durations were quick conversion, effective medications at treatment start, good tolerance to regimens, and low frequency of bilateral cavitation. Recently, the WHO recommended the use of a shorter standard MDR-TB regimen under specific conditions [11]. The feasibility of implementing shorter MDR-TB treatment regimens utilising delamanid is currently being explored in several studies [12].

Adverse events were consistent with symptoms and complications of TB and comorbidities, and do not appear to add to the frequency or severity of previously reported adverse events for delamanid [13, 14]. Notably, QTc interval prolongation was of lower frequency than reported in clinical trials, reflecting other reports from the use of delamanid in programmatic settings [12, 13]. Furthermore, consistent with data throughout its clinical development programme, delamanid did not contribute to hepatotoxicity [12-16].

This study supports the effectiveness and safety of delamanid in the treatment of MDR-TB in a programmatic setting, and reflects the current favourable outcomes in MDR-TB patients with advanced disease treated within Latvia's state programme for treatment of lung disease.

Liga Kuksa ${ }^{1}$, Linda Barkane ${ }^{1}$, Norbert Hittel ${ }^{2}$ and Rajesh Gupta ${ }^{3}$

${ }^{1}$ Riga East University Hospital for TB and Lung Disease Centre, Riga, Latvia. ${ }^{2}$ Otsuka Novel Products GmbH, Munich, Germany. ${ }^{3}$ Otsuka Pharmaceutical Development and Commercialization, Inc., Rockville, MD, USA. 
Correspondence: Norbert Hittel, Otsuka Novel Products GmbH, Erika-Mann-Str. 2180636 Munich, Germany. E-mail: NHittel@otsuka-onpg.com

Received: June 012017 | Accepted after revision: Aug 252017

Conflict of interest: Disclosures can be found alongside this article at erj.ersjournals.com

\section{References}

1 European Centre for Disease Prevention and Control/WHO Regional Office for Europe. Tuberculosis surveillance and monitoring in Europe 2017. Stockholm, European Centre for Disease Prevention and Control, 2017.

2 Miller TL, Cirule A, Wilson FA, et al. The value of effective public tuberculosis treatment: an analysis of opportunity costs associated with multidrug resistant tuberculosis in Latvia. Cost Eff Resour Alloc 2013; 11: 9.

3 Blair HA, Scott LJ. Delamanid: a review of its use in patients with multidrug-resistant tuberculosis. Drugs 2015; 75: 91-100.

4 Matsumoto M, Hashizume H, Tomishige T, et al. OPC-67683, a nitro-dihydro-imidazooxazole derivative with promising action against tuberculosis in vitro and in mice. PLoS Med 2006; 3: e466.

5 World Health Organization. The use of delamanid in the treatment of multidrug-resistant tuberculosis. Interim policy guidance. WHO/HTM/TB/2014.23. Geneva, World Health Organization, 2014.

6 Latvia-Ministry-of-Health. National TB treatment guidelines, Latvia. Riga, Latvia, National TB Programme, 1997.

7 World Health Organization. Treatment of Tuberculosis: Guidelines. 4th Edn. WHO/HTM/TB/2009.420. Geneva, World Health Organization, 2009.

8 Tadolini M, Garcia-Prats AJ, D’Ambrosio L, et al. Compassionate use of new drugs in children and adolescents with multidrug-resistant and extensively drug-resistant tuberculosis: early experiences and challenges. Eur Respir $J$ 2016; 48: 938-943.

9 Banerjee R, Allen J, Westenhouse J, et al. Extensively drug-resistant tuberculosis in California, 1993-2006. Clin Infect Dis 2008; 47: 450-457.

10 Kuksa L, Riekstina V, Leimane V, et al. Multi- and extensively drug-resistant tuberculosis in Latvia: trends, characteristics and treatment outcomes. Public Health Action 2014; 4: Suppl. 2, S47-S53.

11 Falzon D, Schuenemann HJ, Harausz E, et al. World Health Organization treatment guidelines for drug-resistant tuberculosis, 2016 update. Eur Respir J 2017; 49: 1602308.

12 Otsuka Pharmaceutical. Progress in Otsuka's FighTBack Initiative. Presented at the Working Group on New TB Drugs (WGND) Meeting. Liverpool, UK, October 2016. www.newtbdrugs.org/sites/default/files/meetings/files/08_ Otsuka\%20Update\%20for\%20WGND\%20meeting\%20Oct\%202016\%20FINAL.pdf Date last accessed: September 04, 2017.

13 Gler MT, Skripconoka V, Sanchez-Garavito E, et al. Delamanid for multidrug-resistant pulmonary tuberculosis. N Engl J Med 2012; 366: 2151-2160.

14 Skripconoka V, Danilovits M, Pehme L, et al. Delamanid improves outcomes and reduces mortality in multidrug-resistant tuberculosis. Eur Respir J 2013; 41: 1393-1400.

15 Hafkin J, Hittel N, Martin A, et al. Early outcomes in MDR and XDR-TB patients treated with delamanid under compassionate use. Eur Respir J 2017; 41: 1700311.

16 Gupta R, Wells CD, Hittel N, et al. Delamanid in the treatment of multidrug-resistant tuberculosis. Int $J$ Tuberc Lung Dis 2016; 20: Suppl. 1, S33-S37. 